\title{
VII. Analysis of the spinel ruby
}

\section{Vauquelin}

To cite this article: C. Vauquelin (1799) VII. Analysis of the spinel ruby , Philosophical Magazine Series 1, 3:9, 41-49, DOI: 10.1080/14786449908676953

To link to this article: http://dx.doi.org/10.1080/14786449908676953

\section{曲 Published online: 18 May 2009.}

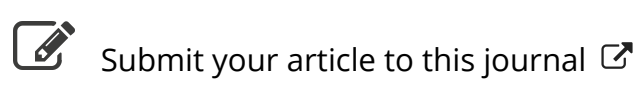

LII Article views: 4

Q View related articles ¿ 
the tides and currents; and others, a change in the earth's centre of gravity, occafioned either by depofits tranfported by rivers to the fea, or by the progreffive movement of fome mafs detached from the interior parts of the earth fuppofed to be concave* .

[To be continned.]

VII. Analyfs of the Spinel Ruby. By C. VAUQUeLIN, Inspector of Mines and Member of the Frencb National Infitute. From Journal des Mines, No. XXXVIII.

I

RON and manganefe have long been confidered as almoft the only metals employed by nature to colour minerals; but though thefe metals may affume a multitude of different fhades according to the proportions of oxygen which they contain, we however often fee in nature bodies poffeffed of colours which neither iron nor manganefe ever formed artificially or naturally when pure, and it is probable that we fhall one day find many other colouring metals and alfo ftones and earths.

I have already announced that the colour of the emerald, which all chemifts afcribed to iron, is owing to the oxyd of chrome. In examining the peculiar red colour of the fpinel ruby with the refults of the analyfis lately made of it by Profeffor Klaproth, I began to doubt of that rich and beautiful colour being produced by the oxyd of iron, of which the Profeffor found only I.5 in Ioo + . My doubts in this refpect were ftill increafed by reading in Bergmann that the ruby fufed with borax communicates to it a beautiful green

* 12. To obferve whether there are not daily formed different kinds of ftones in the places which are wathed by the waters of the fea. $C$.

+ The number, nature and proportion of the principles found by Klap. roth in the fpinel ruby are ftated as follows: Alumine 76 ; fliceous earth 16; magnefia 8; oxyd of iron $x 5$; - Total xor's.

colour, 
colour, as well as by a paffage of Klaproth, in which he fays, that magnefia extracted from that precious ftone, being diffolved in the fulphuric acid, had given to it a green colour. The rubies of different colours preferved in collections, fuch as the fapphire-blue in the poffeffion of the Hon. Mr. Greville, the green belonging to Mr. Hawkins, and the white in the collection of Mr. Macie of London, authorifed me to fufpect that iron is not the colouring principle of that ftone.

Thefe different confiderations induced me to make a new analyfis of the fpinel ruby: and the refult of this labour will prove, that my doubts were not without foundation, and that it not only does not contain a fingle particle of the oxyd of iron, but that there is even no filiceous earth in it, as announced by Klaproth. The rubies employed for this analyfis were cryftallifed, tranfparent, and free from any foreign mixture.

Exp. I. A hundred parts of this ftone being expofed to a violent heat, loft nothing of their weight, but their tint was weakened and changed to a rofe colour.

II. A hundred parts of the fame ftone reduced to a fine powder, and ftrongly heated in a charcoal crucible, were agglutinated into one mafs of a greenifh grey colour.

III. A hundred parts of the fmall fragments of rubies reduced to an impalpable powder in a mortar of filex, were increafed five parts.

IV. I heated for an hour, in aflver crucible, roo parts of a ruby thus pulverifed, with 300 parts of cauftic potafh: the mix ture was not fufed; on the contrary it was reduced to a pulverulent mafs of a green colour, of which fome particles were merely agglutinated. I mixed this with diftilled water, in which it was all fo nearly diffolved that there remained of it only fome particles which weighed fcarcely three parts. I poured upon the folution, which remained ftill mixed with the undiffolved matter above-mentioned, fome diluted muriatic acid. The firft portions of this acid made the folution affume the appearance of a mafs as thick as foup (bouillie), which was rediffolved, 
diffolved, at leaft for the greater part, by additional quantities of the acid. I warmed the folution by a gentle heat, and having filtered it, there remained on the paper three parts of a rofe-coloured powder, which was ruby, not decompofed. This I placed apart, that I might operate only on that portion which had been attacked.

$\mathrm{V}$. The muriatic folution above mentioned having been evaporated to drynefs by a gentle heat, I poured upon the refiduum a large quantity of diftilled water : almoft the whole of it was diffolved. There remained only five parts of a grey powder, which melted with borax, to which it communicated a green colour.

VI. I fubjected thefe five parts to different tefts, which thewed, that they were filiceous earth mixed with a little alumine, and coloured by a matter, of which I thall fpeak hereafter*.

VII. I precipitated the muriatic folution of Exp. V. with carbonat of ammonia. When I judged that I had added a fufficient quantity, I boiled the mixture for a quarter of an hour, in order to expel the carbonic acid, and favour the precipitation of the lime or magnefia, if there were any of thefe in it. By thefe means I obtained an abundant white precipitate, which I boiled with a folution of cauftic potafh. The greater part of this precipitate was diffolved. There remained only I $\frac{x}{2}$ parts of a brown fubftance inclining to violet, but which turned to a yellowifh-green colour, by drying in a gentle heat.

* In another analyfis of the ruby I had for refiduum, after the evaporation of the muriatic folution, but five parts and a half of filiceous earth, Alightly coloured green, and without any mixture of alumine. This difference arifes frotn the degree of heat given to the matter towards the end of the evaporation, or from the faline mals not being equally firred throughout. In the latter cafe it happens that there are parts which dry too much, and others which do not dry fufficiently. Hence it happens that moleculz of alumine are abandoned by the acid, while moleculæ of filex remain combined; and this was the cafe in my frit analyfis. 
VIII. Thefe $10_{\frac{x}{2}}^{x}$ parts were diffolved by the fulphurie acid. The folution had a greenifh colour. This folution mixed with the faturated carbonat of potafh, precipitated a greenifh matter, which, when wafhed and dried, weighed two parts. A fmall portion of this precipitate melted with borax communicated to it a beautiful emerald green colour *. This matter, which I placed apart, I thall fpeak of hereafter.

IX. As I had diffolved in the fulphuric acid 10.5 of mat ter, and as the carbonat of potafh precipitated only 2 , there muft have remained 8.5 in the folution. Sufpecting therefore that the matter was retained there by an excefs of the carbonic acid, I boiled the liquor for fome minutes, and I obtained a white granulated precipitate, weighing I6 parts, which by calcination were reduced to 8 . This matter, combined with the fulphuric acid, gave a falt cryftallifed in tetraedral prifms, terminated by pyramids with four faces, the tafte of which was firf fweet, and afterwards bitter; which was not precipitated by the faturated carbonat of potalh; was only partly fo by ammonia; and, in a word, which prefented all the characters of fulphat of magnefia. The ruby therefore, according to this experiment, fhould contain 8 parts of magnefia in 100 ; but as $\frac{x}{2}$ part was wanting in that fubjected to experiment, we may eftimate the quantity at $8 \cdot 5$.

In heating the colouring matter of the ruby with borax over charcoal, and ftopping the operation before the effervefcence had ceafed, I have twice obtained a vitreous globule of a red colour, perfectly fimilar to that of the ruby; but in heating again this red globule, the effervefence was renewed, and the globule became of an emerald green colour. In vain did I afterwards try to make the red colour re-appear, whether I applied the exterior or the interior flame of the blow-pipe. It is even very diffcult to obtain, in the firtt inftance, the vitreous globule of a red colour. It is neceffary for that purpofe that the colouring matter fhould not touch the charcoal; that it thould not be added till the borax is melted; and that it hould be heated with the exterior flame. Though $I$ often attempted to produce this phenomenon, I never fucceeded but twice. 
$X$. I vinited the five parts of Ex. VI. and the two parts of Ex. IX; boiled them five or fix times fucceffively in a porcelain veffel with concentrated nitric acid, evaporating each time to drynefs. The matter at firft affumed a beautiful dark green colour, and at the end of each operation it boiled and was puffed up like alum. At laft, when the greater part of the acid was evaporated, and the matter began to dry, it affumed an orange yellow colour. After treating the matter in this manner, I mixed with it a little pure cauftic potafh; and when the mixture was well formed and reduced to a kind of pafte, I diluted it with diftilled water, in which almoft the whole of the matter was diffolved. Nothing remained but a little grey mătter which weighed about $I_{\frac{x}{2}}$ parts, and which I found to be fliceous earth. The alkaline folution had a weak golden yellow colour; and as it contained an excefs of alkali, I added, in order that it might be faturated, a few drops of nitric acid. By this addition there was produced a light white precipitate, which weighed at moft one part, and which appeared to me to be alumine. The liquor had then a reddifh colour.

XI. As I fufpected, from all the phenomena which had appeared during the courfe of this analyfis, that the colouring matter of the ruby was chrome, I mixed the liquor of the preceding experiment, firt, with nitrat of lead, and I immediately obtained a precipitate of a beautiful orangeyellow colour; fecond, with nitrat of mercury, and there was produced a depofit of a cinnabar red colour ; and, third, with the nitrat of filver, which gave a precipitate of a crimfon red colour. I was convinced by thefe phenomena that the ruby, like the emerald of Peru, contains a certain quantity of chrome, to which it is indebted for its colour. But it feems difficult at firft to reconcile the colour of the emerald with that of the ruby, by referring them to the fame fubftance; for nothing feems more remote from green than red. If we however recollect that this metal is fufceptible 
of affuming different colours according to the quantities of oxygen which it abforbs; that when it is faturated with this principle, it is red and acid; and when it contains lefs, it is green, and in the ftate of an oxyd, we thall readily conceive how this oxydated metal may colour the emerald and the ruby. It follows then from thefe confiderations, that chrome exifts in the emerald in the ftate of an oxyd, and in the ruby in the ftate of an acid; and that this acid is there, doubtlefs, in a faline combination with alumine or magnefia, and perhaps with both at the fame time. With regard to the proportion of the chromic acid in the ruby, I have not been able to determine it very accurately, on account of the affinity which it has with alumine, from which it is difficult to feparate it completely. I am however of opinion that it may be eftimated, without committing any very fenfible error, at between 5 and 6 parts in 100 of ruby.

XII. I now return to the folution of alumine in cautic potafh (Exp. VII.). I fuper-faturated it with the muriatic acid, and precipitated it afterwards by the carbonat of ammonia. The depofit wathed and kept at a red heat for a confiderable time weighed 85 parts. This matter had all the properties of alumine. As I had however fcarcely found any fliceous earth during the courfe of this analyfis, and as Klaproth fays that he obtained 16 in 100 parts of this ftone, I withed to affure mylelf whether there might not be fome of it remaining in the alumine. For that purpofe I diffolved the 82 parts above-mentioned in the fulphuric acid, and I indeed obtained an infoluble refiduum which weighed three parts, and which was filiceous earth. This, with the $\mathbf{I}_{2}^{*}$ part obtained (Exp. X.), makes $4 \frac{\mathrm{x}}{2}$ parts. But it muft be recollected, that during the pulverifation of the roo parts of ruby, the details of the analyfis of which $I$ have explained, 5 parts were taken from the mortar of filex; from which it follows, that the $4 \frac{\mathrm{t}}{2}$ parts of this fubftance found in the courfe of thefe operations did not belong to the ruby, Whatever method 
method I employed, and whatever care I took, I could never obtain a larger quantity, and therefore it is very probable that Klaproth was deceived in this refpeet.

Now, to eftablifh the proportions of the principles of the ruby, I muft here obferve, that of 100 parts fubjected to analyfis, 97 only were attacked; but 97 having furnifhed 85 of alumine (Exp. XII.), 3 of which were to be taken away for the filiceous earth, Ioo would have given 82.47 ; 8.5 of magnefia having been obtained from thefe $97,8.78$ would have been found in 100 . In the like manner, inftead of 6 of the chromic acid, we hould have had $6 \cdot 18$. Thus, IoO parts of fpinel ruby confift of alumine 82.47 , magnefia $8 \cdot 78$, chromic acid 6.18. Lofs $2 \cdot 57$. Total 100 .

XIII. To prove the correctnefs of the refults of the preceding analyfis, I repeated it by following another method. I heated 100 parts of ruby, reduced to a fine powder, for feveral hours with concentrated fulphuric acid. I obtained a folution, almoft complete, by the addition of a fufficient quantity of water. There remained nothing but 5 or 6 parts of a grey powder, which had all the characters of filiceous earth, and which was only mixed with a little chrome.

The folution evaporated to the confiftence of fyrup gave radiated cryftals without folidity; but thefe cryftals, re-diffolved in water, and the folution mixed with a fufficient quantity of the fulphat of potafh, gave octaedral cryftals of alum. The whole 100 parts of the ruby thus diffolved in the fulphuric acid furnifhed me, in feveral fucceflive cryftallifations, with about 800 parts of alum, without reckoning the latter portions which I could not entirely feparate from the mother water. This mother water had a green colour, and a bitter flightly metallic tafte. I diluted it with water, and mixed with it a folution of the carbonat of potalh. There was formed a greenifh white precipitate, which was a mixture of alumine and the oxyd of chrome. The liquor filtered

* The $f_{d m e}$ article in the Annales de Chemie, Meffidor An. VI. fates this product at 775 . EDIT. 
and expofed to heat depofited a white powder, which, wafhed and dried, weighed $I 7$ parts, that were reduced to $8 \cdot 3$ by calcination. They confifted of magnefia, ftill mixed with $\mathbf{a}$ few particles of oxyd. The precipitate formed in the mother water by the carbonat of potafh was treated with a folution of cauftic potafh. By thefe means the alumine was diffolved, and the oxyd of chrome remained without undergoing any fenfible alteration : it weighed 5 parts.

This analyfis perfectly confirms the former; for, fome fight differences in the proportions excepted, it abfolutely gave the fame refults. It proves above all that the ruby does not contain filiçeous earth, and that the fmall quantity found in the products was furnifhed by the mortar in which the ftone was pounded.

I muft here obferve, that it does not always happen that the whole mafs of the ruby is diffolved during the firft operation. There remains fometimes feveral parts which have undergone no alteration. This depends on the time employed for ebullition, and ftill more on the degree of finenefs to which the ftone is reduced before it is fubjected to trial. But when that happens, after having wafhed the refiduum, which is infoluble in the acid, it muft be dried, pounded again, and treated in the fame manner as before. Nothing then ought abfolutely to remain but the filiceous earth belonging to the mortar.

XIV. The muriatic acid diffolves the ruby alfo: but a confiderable portion of it is required; becaufe it volatilifes in a moderate heat, and without a ftrong degree of heat it makes no fenfible impreffion on that fubftance. I obferved that this acid diffolves the principles of the ruby in the fame proportions as they hold between themfelves in the ftone; for the portion not attacked abfolutely preferves the fame thade of colour as that which it had before fubjected to the action of the acid. This proves that it does not diffolve one principle in preference to another, and that they are in a ftate of real combination in the ruby. 
From thefe confiderations it would appear natural to confider the ruby as a faline fubftance, compofed of two bafes, alumine and magnefia, and of an acid called the chromic acid.

When I announced to the National Infitute that I had not found magnefia in the ruby, I was however far from imagining that Klaproth was deceived; fo much confidence did I place in the labours of that able chemift. I chofe rather to conclude at that time, that the ruby I had examined was different from his. But $I$ was in an error in that refpect, as $I$ was convinced by a new analyfis, which I made of about I6 grammes of the fame ruby; and it was from this latter labour, carried on in a manner fomewhat different, that I eftablifhed the proportions of the principles of this ftone, as already enumerated. This proves the neceffity of employing rather large maffes, in order to find fmall quantities of matter. I thought it my duty to make this public acknowledgement, both that I might render juftice to accuracy and to the fagacity of a man who has given fo many proofs of it, and to avoid the reproach which might have been thrown out againft me, of wifhing to conceal an error into which $I$ had fallen.

VIII. Defcription of a remarkable Spring of Frefb Water, wubicb rifes tbrough the Water of the Sea. By the Abbe SPallanzani. From the Journal de Phyfique, Vol.XXIX.

IIIS fpring rifes through the falt water at the diftance
of fixty-five feet from the thore and about a mile from Spez-
zia. It raifes itfelf fome inches above the furface of the fea,
and forms a fort of accumulation, thaped like a button of
about twenty feet in diameter. This button, when the ea
is perfectly calm, is full of watery radii, exceedingly percep-
tible. The water of which they are formed feems a little
turbid; and this is very apparent, efpecially when it has
Vox. III. 